\title{
Kidney transplantation during the COVID-19 pandemic period: a single center experience
}

\author{
Emre Karakaya ${ }^{1}$, Aydincan Akdur ${ }^{1}$, Ebru H. Ayvazoglu Soy ${ }^{1}$, Emin Turk ${ }^{1}$, Feza Karakayali ${ }^{1}$ C. Burak Sayin ${ }^{1}$, Esra Baskin², \\ Sedat Yildirim ${ }^{1}$, Gokhan Moray ${ }^{1}$, Mehmet Haberal ${ }^{1}$ \\ ${ }^{1}$ Department of Surgery, Baskent University, Ankara, Turkey \\ ${ }^{2}$ Department of Pediatric Nephrology, Baskent University, Ankara, Turkey
}

Background: When the COVID-19 pandemic has started, it had the immediate effect of severely reducing organ donation and transplantation activity worldwide. Our early experience showed that neither hemodialysis nor transplant patients have got infected with COVID-19 higher than the normal population. While it seems obvious that life-saving transplant activity should not be stopped, it should be tailored with careful selection of both donors and recipients within transparency and considering ethical and legal aspects.

Methods: Despite many studies have indicated that elective transplantations should be postponed during pandemic period, we decided to continue our transplant activities in a controlled manner at our three centers. From March 1, 2020, to August 10, 2021, we performed 127 kidney transplants (112 adults, 15 pediatrics). All recipients were given a routine immunosuppressive protocol. We reviewed the medical records of both recipients and donors, polymerase chain reaction tests have been carried out twice before transplantation, and they were screened with thoracic computed tomography.

Results: Kidney transplants were performed from 121 living related and six deceased donors with an average length of hospital stay 9.4 days. Mean serum creatinine values of the recipients were $0.94 \mathrm{mg} / \mathrm{dL}, 0.82 \mathrm{mg} / \mathrm{dL}$, and $0.74 \mathrm{mg} / \mathrm{dL}$ at postoperative day 7 , 30 and 90 , respectively and all recipients were discharged successfully. Out of 106 kidney transplants, 105 patients are alive with normal kidney function and one patient died to due to cardiac problem.

Conclusions: When precautions are taken, transplant does not pose a risk to patients during the pandemic period. The safety and success of our transplantation activities lies in our newly developed protocol in response to the COVID-19 pandemic.

Corresponding author: Emre Karakaya

E-mail: rectorate@baskent.edu.tr

(c) The Korean Society for Transplantation

This is an Open Access article distributed under the terms of the Creative Commons Attribution Non-Commercial License (http://creativecommons.org/licenses/by-nc/4.0/) which permits unrestricted non-commercial use, distribution, and reproduction in any medium, provided the original work is properly cited. 